\title{
Palliative care integration: a critical review of nurse migration effect in Jamaica
}

\author{
Rebecca L. Edwards ${ }^{1 *}$ (D) Patricia A. Patrician ${ }^{2}$, Marie Bakitas ${ }^{3}$ (D) and Adelais Markaki ${ }^{4}$ (D)
}

\begin{abstract}
Background: Provision of palliative care to individuals with late-stage serious illnesses is critical to reduce suffering. Palliative care is slowly gaining momentum in Jamaica but requires a highly skilled workforce, including nurses. Outmigration of nurses to wealthier countries negatively impacts the delivery of health care services and may impede palliative care capacity-building. This critical review aimed to explore the evidence pertaining to the nurse migration effect on the integration of palliative care services in Jamaica and to formulate hypotheses about potential mitigating strategies.

Methods: A comprehensive search in the PubMed, CINAHL, and ProQuest PAIS databases aimed to identify articles pertinent to nurse migration in the Caribbean context. Grant and Booth's methodologic framework for critical reviews was used to evaluate the literature. This methodology uses a narrative, chronologic synthesis and was guided by the World Health Organization (WHO) Public Health Model and the Model of Sustainability in Global Nursing.

Results: Data from 14 articles were extracted and mapped. Poorer patient outcomes were in part attributed to the out-migration of the most skilled nurses. 'Push-factors' such as aggressive recruitment by wealthier countries, lack of continuing educational opportunities, disparate wages, and a lack of professional autonomy and respect were clear contributors. Gender inequalities negatively impacted females and children left behind. Poor working conditions were not necessarily a primary reason for nurse migration. Four main themes were identified across articles: (a) globalization creating opportunities for migration, (b) recruitment of skilled professionals from CARICOM by high income countries, (c) imbalance and inequities resulting from migration, and (d) mitigation strategies. Thirteen articles suggested education, partnerships, policy, and incentives as mitigation strategies. Those strategies directly align with the WHO Public Health Model drivers to palliative care integration.

Conclusion: Emerged evidence supports that nurse migration is an ongoing phenomenon that strains health systems in Caribbean Community and Common Market (CARICOM) countries, with Jamaica being deeply impacted. This critical review demonstrates the importance of strategically addressing nurse migration as part of palliative care integration efforts in Jamaica. Future studies should include targeted migration mitigation interventions and should be guided by the three working hypotheses derived from this review.
\end{abstract}

Keywords: Palliative care, Integration, Nurse migration, Jamaica, CARICOM, Caribbean, Critical review

*Correspondence: rledwards@uab.edu

${ }^{1}$ Department of Acute, Chronic, and Continuing Care, School of Nursing,

University of Alabama at Birmingham, 1720 2nd Avenue South,

Birmingham, AL 35294-1210, USA

Full list of author information is available at the end of the article

\section{Background}

Palliative care is a team-based holistic approach that focuses on improving quality of life and reducing suffering in those with serious illnesses [1, 2]. It is well-established that palliative care should be integrated at the time of diagnosis or early in the serious illness trajectory [3-8]. The United Nations (UN) has declared palliative 
care a human right [9] and the World Health Organization (WHO) has called for governments to integrate primary palliative care in the continuum of care, as part of universal health coverage schemes [10]. In the United States of America (USA), palliative care is available through specialized teams in $72 \%$ of larger hospitals [11]. In contrast, palliative care in Jamaica is provided by only two specialists [10] at hospital-based clinics in three out of 24 public hospitals. Community-based palliative care is largely unavailable, with only a few privately funded small initiatives, and nearly all palliative care recipients have cancer diagnoses [12, 13]. Thus, limited palliative care availability in Jamaica leads to a significant disparity for patients with serious illnesses. An adequately trained and available healthcare workforce is necessary to ensure access to quality palliative care. However, the migration of health workers, and particularly of nurses, stands out as a potential barrier. Understanding the phenomenon of nurse migration and ensuring that adequately skilled nurses are retained is of utmost importance in palliative care integration efforts, especially in light of the ongoing COVID-19 pandemic.

Health personnel migration takes place in the context of larger migration trends [14] and leads to inadequate health system performance in developing countries [15]. Typical migratory patterns involve health personnel leaving developing countries, such as Jamaica, and relocating in wealthier countries such as the USA, the United Kingdom, and Canada, resulting in an overall inequitable and unsustainable balance [16]. Shortages secondary to migration and other factors constitute a major threat to less developed health systems and to global health security [17], undermining efforts to meet the UNs' Sustainable Development Goals (SDGs) [18]. In 2010, the WHO Global Code of Practice on International Recruitment of Health Personnel [19] was adopted to serve as a framework for global dialogue and cooperation, mainly around recruitment from developing countries facing critical shortages of health personnel [19]. The Code calls for more ethical recruitment, avoidance of recruitment from countries with skilled health worker shortages, and careful monitoring of international mobility of health workers [14].

Nurse migration has been viewed as a potential threat to global health security [7]. Although nurses make up more than half $(59 \%)$ of the world's healthcare workforce, accounting for 27.9 million, the overall shortage of nurses was estimated at 5.9 million in 2018 [20, 21]. The importance of nurses in achieving the SDGs and universal health is underscored by the State of the World's Nursing 2020 Report [21]. Severe nursing shortages in developing countries, compounded by aging populations, increased health service specialization, and technological complexity are major contributors to nurse migration [22]. In the Caribbean, nurses migrate for many reasons including better remuneration, improved work conditions, and career advancement [23, 24]. Historically, nurse migration has resulted in an imbalance of the skilled nursing workforce favoring wealthier countries; a phenomenon expected to continue in Jamaica and the wider Caribbean without significant intervention [16].

The Caribbean Community and Common Market (CARICOM) is a group of 20 developing countries in the Caribbean that have united to improve standards of living and work and to enhance levels of international competitiveness [25]. A scoping review by Rolle Sands et al., which was published after our search was completed, examined the conceptual and empirical literature pertaining to nurse out-migration from the CARICOM region [24]. Their findings supported a need for future research on the impact of nurse migration on health systems and population health within Caribbean countries. Furthermore, the need to address palliative care educational deficits in the Caribbean and, more specifically, in Jamaica has been underscored [13]. Jamaica, an English-speaking country with a population of 2.8 million, is a CARICOM member state that has been profoundly affected by nurse migration [26]. Jamaica has the highest emigration rate in the CARICOM; 745,000 (16.9\%) in 2017, with skilled professionals consistently constituting a high share of those who emigrate [27]. In fact, $85 \%$ of Jamaica's skilled labourors emigrated to wealthier countries from 1965 to 2000; twelve times higher than emigration rates of wealthier countries and eight times higher than the world average [28]. Jamaica's nursing shortage is a product of longstanding nursing shortages in wealthier countries [29, 30] coupled by increasing global demand due to aging and patient care complexities [31]. Nurse burnout related to high patient care stress in wealthier countries exacerbates the demand for Jamaican nurses, as does an overall shortage of nurse faculty, which causes qualified student applicants to be turned away from nursing school admission [32]. Jamaican nurses are attractive recruits because they are English-speaking, have high pass rates on licensure exams, and are highly skilled [33]. These nurses are attracted to wealthier countries by the promise of higher salaries. The starting salary in 2015 for a nurse in Jamaica was $\$ 8000$ compared to $\$ 65,000$ in the USA [34]. Although nurse migration statistics specific to Jamaica are not readily available, in 2018 , the density of nurses per 10,000 population was 8.07 in contrast to 13.36 in the USA [35]. By 2025, the projected unmet demand for nurses in the CARICOM region will be 10,700 [36]. The Jamaican Minister of Health, Dr. Christopher Tufton, proclaimed, "brain 
drain [a slang term for migration] has virtually crippled the delivery of certain health care services and has had a dramatic effect on the overall quality of health care [in Jamaica] [17]."

Given the escalating nursing shortage, it is important to factor migration into palliative care expansion efforts in Jamaica. The country's Strategic Plan and Action Plan for the Prevention and Control of Cancer offers evidence that palliative care is gaining momentum [37]. Nursing attributes align naturally with core fundamentals of palliative care, thus, nurses are ideally suited to lead efforts to integrate palliative care, as long as they can be trained and retained [38]. To effectively integrate palliative care in a country's health system, the WHO Public Health Model (PHM) calls for policies, availability of essential medicines, and comprehensive education [39, 40]. These components are necessary to ensure that palliative care is embedded in existing health systems and that specialist services are available for the most complex patients. The Sustainability in Global Nursing Model supports that empowering nurses leads to sustainably strengthening the nursing workforce [41].

Guided by the above two models, we examined nurse availability as a facilitator and nurse migration as a barrier to palliative care integration in Jamaica. Our intent was to better understand ways to mitigate 'push-factors'; factors influencing emigration of health professionals from their home country. The Rolle-Sands et al. [24] review identified sustainable partnerships across Jamaica and wealthier countries as important to facilitating autonomy and advancing nursing practice in the CARICOM. These findings align with our academic partnership experiences pursued through two Pan-American Health Organization(PAHO)/WHO Collaborating Centers (WHOCCs); one based at the University of Alabama at Birmingham (UAB) in the USA, and another at the University of West Indies (UWI) in Jamaica. This academic partnership between WHOCCs has led to research immersion, simulation training, visiting scholar exchanges, and development of distanceaccessible courses [42, 43]. Hence, the purpose of this critical review was to explore the evidence pertaining to the nurse migration effect on the integration of palliative care services in Caribbean countries with a special focus on Jamaica, and to formulate hypotheses about potential mitigating strategies. Our guiding questions were: (a) What is the effect of nurse migration on palliative care in Caribbean countries and, specifically, in Jamaica?, (b) What are the potential nurse migration-related barriers to palliative care integration in Jamaica?, and (c) Which nurse migration mitigation strategies should be recommended to optimize palliative care integration in Jamaica?

\section{Methods}

We utilized Grant and Booth's methodologic framework for critical reviews to evaluate the literature following a narrative, chronological synthesis with the goal of developing working hypotheses [44]. This methodology involves: (a) appraisal focused on the article's overall contribution to knowledge; (b) synthesis using a conceptual narrative to identify themes across articles; and (c) analysis of these themes in relation to the WHO PHM [39, 40] and the Sustainability in Global Nursing Model [41].

\section{Search strategy}

The PubMed, CINAHL, and ProQuest PAIS databases were searched to capture biomedical, nursing and allied health, and public health literature. Filters applied were: 1) peer reviewed articles, 2) available in English language, and 3) published between 2004 and July 2019. We sought to identify articles meeting the inclusion criteria: (1) pertinent to nurse migration in a Caribbean context, (2) included information specific to Jamaica, and (3) had potential relevance to palliative care. Search terms across databases included "nurse AND migration AND Jamaica" and "nurse AND migration AND Caribbean". The terms "nurse AND migration AND Jamaica AND Palliative" and "nurse AND migration AND Caribbean AND palliative" did not result in additional relevant articles. The query resulted in 45 articles, with an additional four hand-searched articles added. After removing duplicates, titles and abstracts were screened for relevance, leaving 19 articles for full-text review. These 19 articles were reviewed for inclusion criteria and three articles were eliminated. This left 16 articles that comprised the final yield as displayed in the PRISMA diagram (Fig. 1) [45].

\section{Data extraction and analysis}

Included articles were mapped by origin, type of article, level of evidence, purpose, and key points. This mapping allowed for comparisons and resulted in determination of themes most pertinent to nurse migration in the CARICOM. Appraisal of level of evidence was carried out according to the adapted Rating System for the Hierarchy of Evidence [46, 47].

\section{Findings}

Extracted data from the 16 sampled articles were entered chronologically in Table 1 and emerged themes were determined. Although no articles specifically addressed nurse migration in relation to palliative care, we extracted and synthesized evidence useful in understanding how nurse migration might affect optimal palliative care integration in Jamaica. Only five articles were appraised at level VI in the hierarchy of evidence and included a qualitative case study [48], a qualitative study using focus 


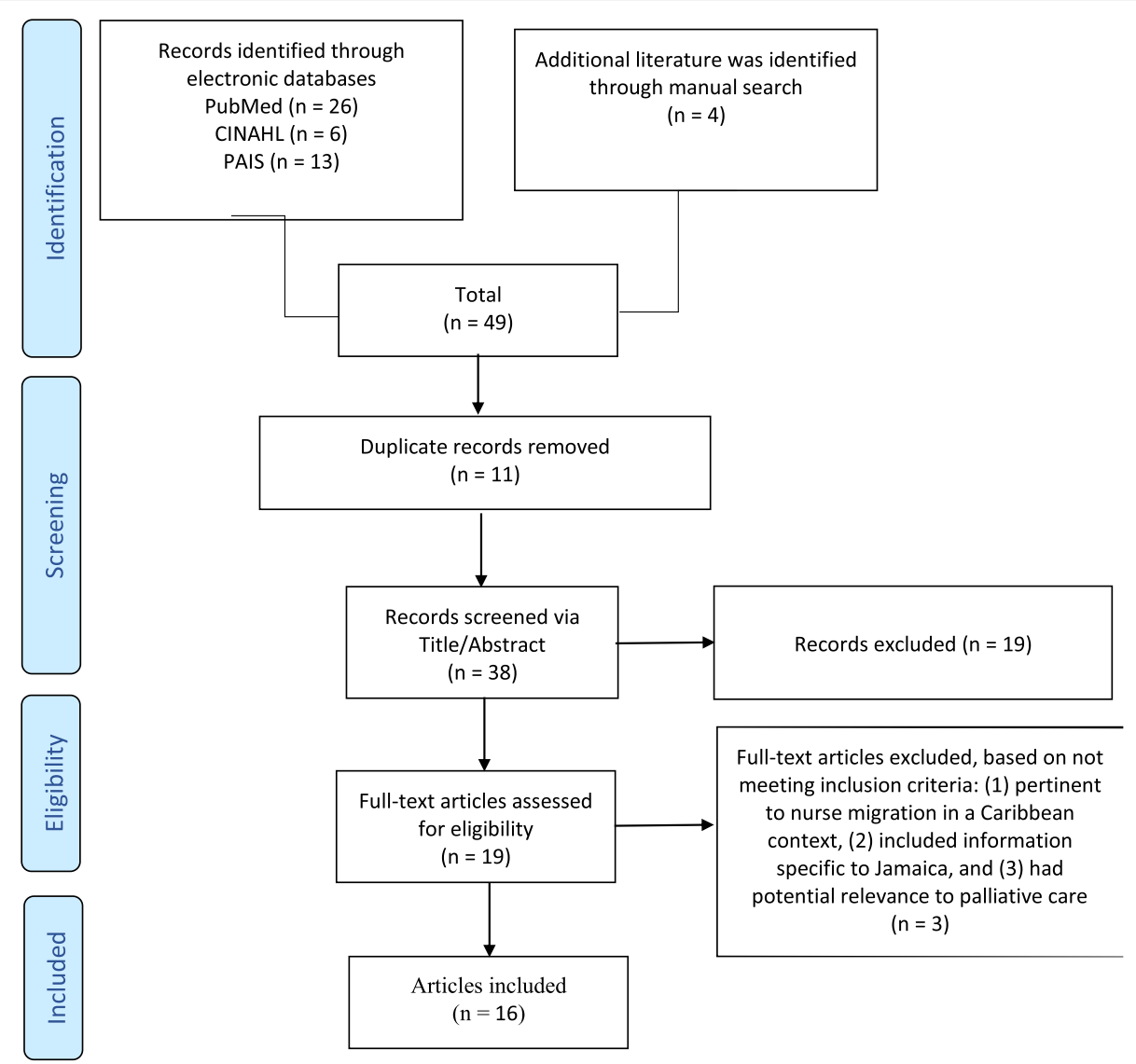

Fig. 1 PRISMA Literature Search Diagram [45]

groups [49], a quantitative exploratory descriptive study [50], a quantitative descriptive correlational study [51], and a mixed methods study [52]. The remaining articles included a literature review (level VII) [53], a World Bank report [54] and an International Organization for Migration (IOM)/UN report (Level VIII) [55], and eight commentaries [29, 30, 32, 33, 56-59]. Four main themes were identified across articles: (a) globalization creating opportunities for migration, (b) recruitment of skilled professionals from CARICOM by high income countries, (c) imbalance and inequities resulting from migration, and (d) mitigation reduction strategies. The distribution of themes by publication year is depicted in Fig. 2 .

\section{Globalization}

The interconnectedness of countries by flow of goods, services, money, people, information, and ideas [61] was highlighted as a key reason for nurse migration [56, 58]. Evans and Tulaney suggested that one must first understand globalization to understand nurse migration [56]. Jacobson added that globalization affects a nurse's decision to migrate based on the benefits associated with this practice (e.g. higher pay and improved workplace conditions) [58]. Higher salaries and the ability to send remittances (i.e., a portion of salary) home are factors in a nurse's decision to migrate. However, other considerations are 'push' factors that lead to out-migration. For instance, high patient-nurse ratios and lacking the resources to adequately care for patients and families. Educational opportunities are few and governments under-invest in nursing education, limiting the ability of predominantly female nurses to advance in the field [58]. Although not specific to palliative care, globalization can potentially negatively impact palliative care integration in countries with low resources.

\section{Recruitment}

Nurse recruitment was highlighted in six articles as a main contributor to nurse migration [29, 30, 33, 54, 56]. Aggressive recruitment by higher income countries leads to a maldistribution of nurses across regions. Nurses with higher education and skill move to wealthier countries leaving more novice nurses in the CARICOM and resulting in nurse shortages, poorer working conditions, and 


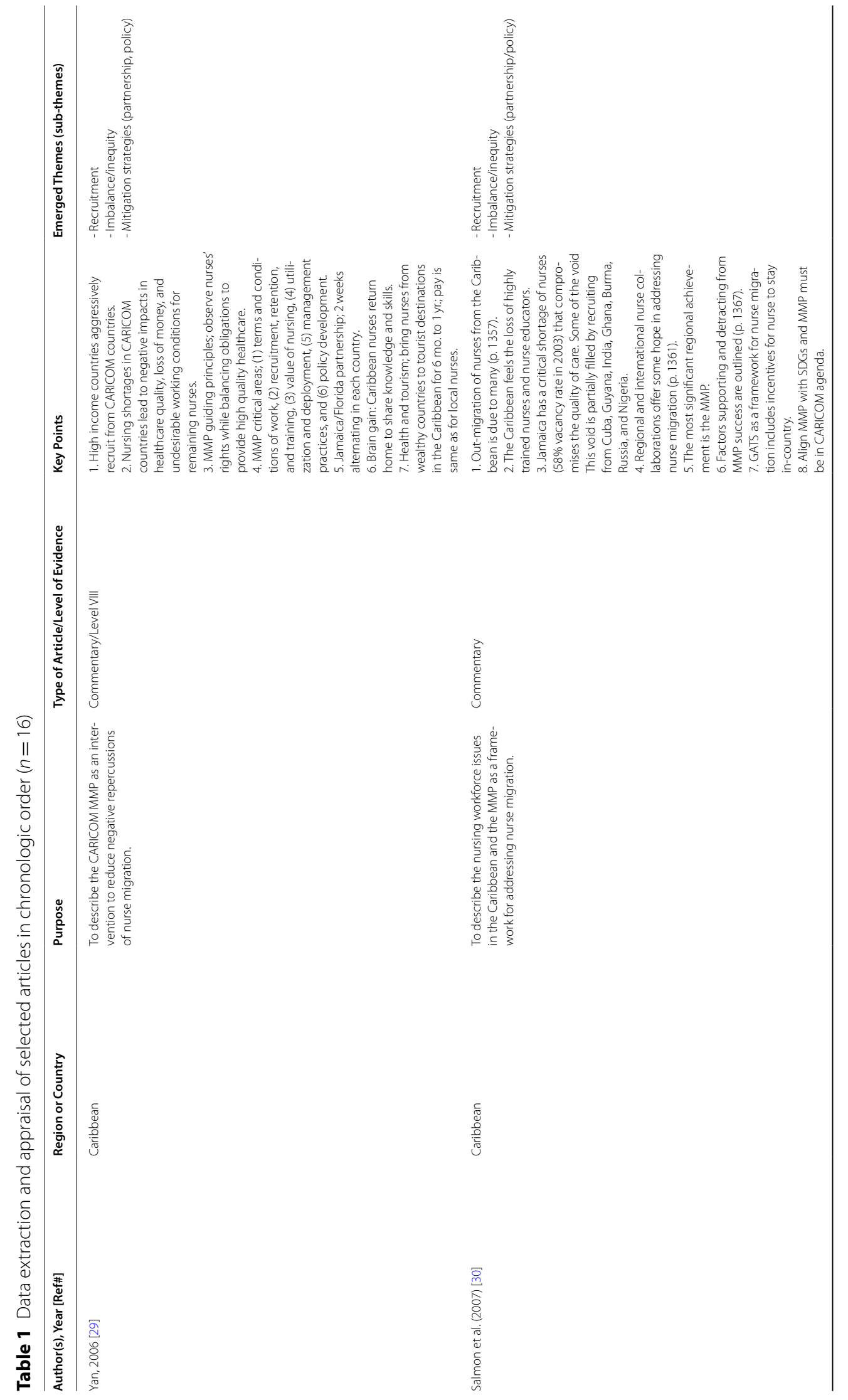




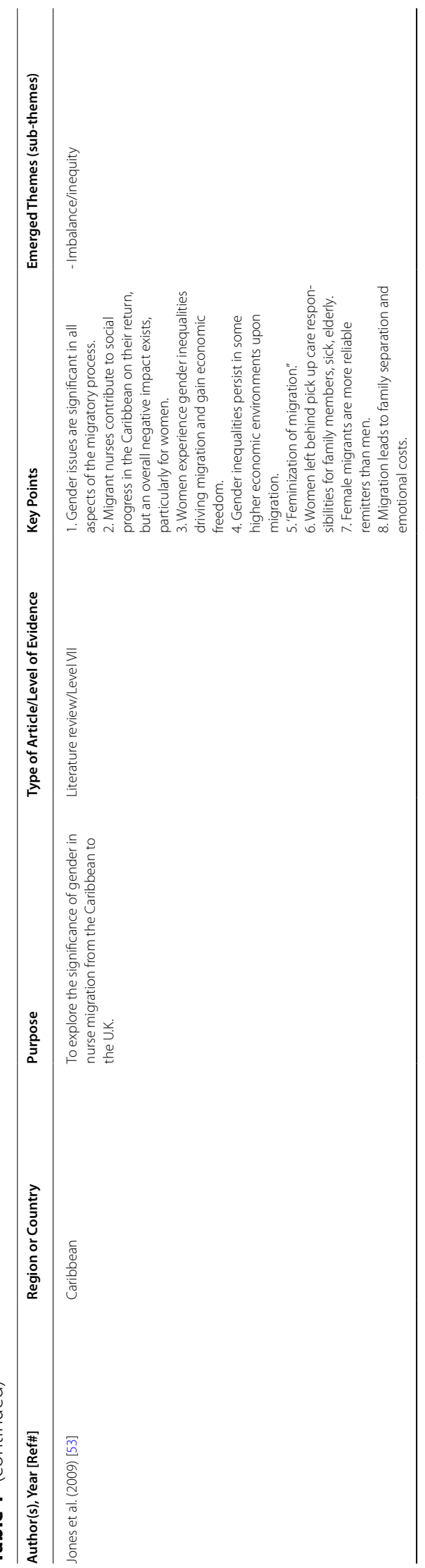




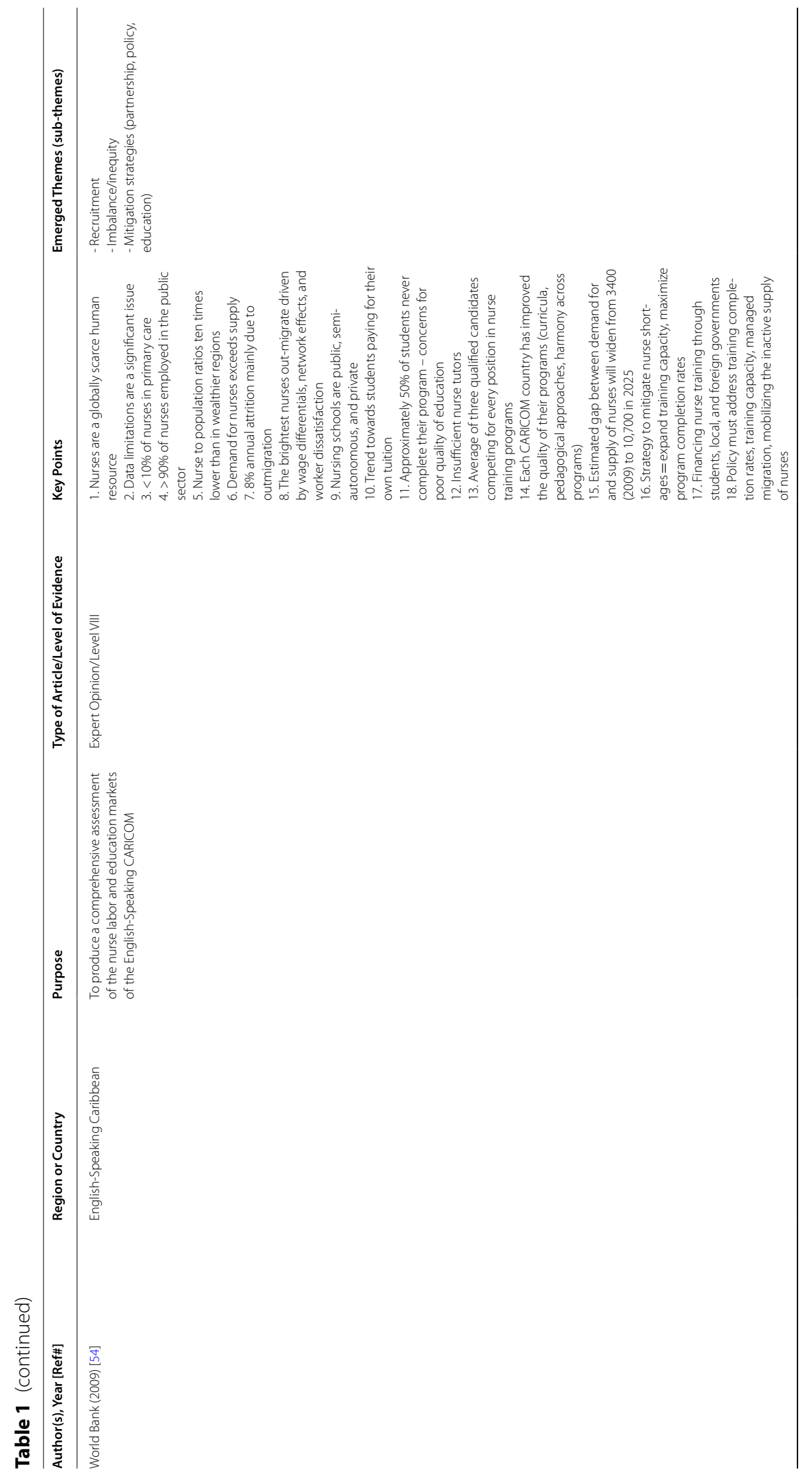




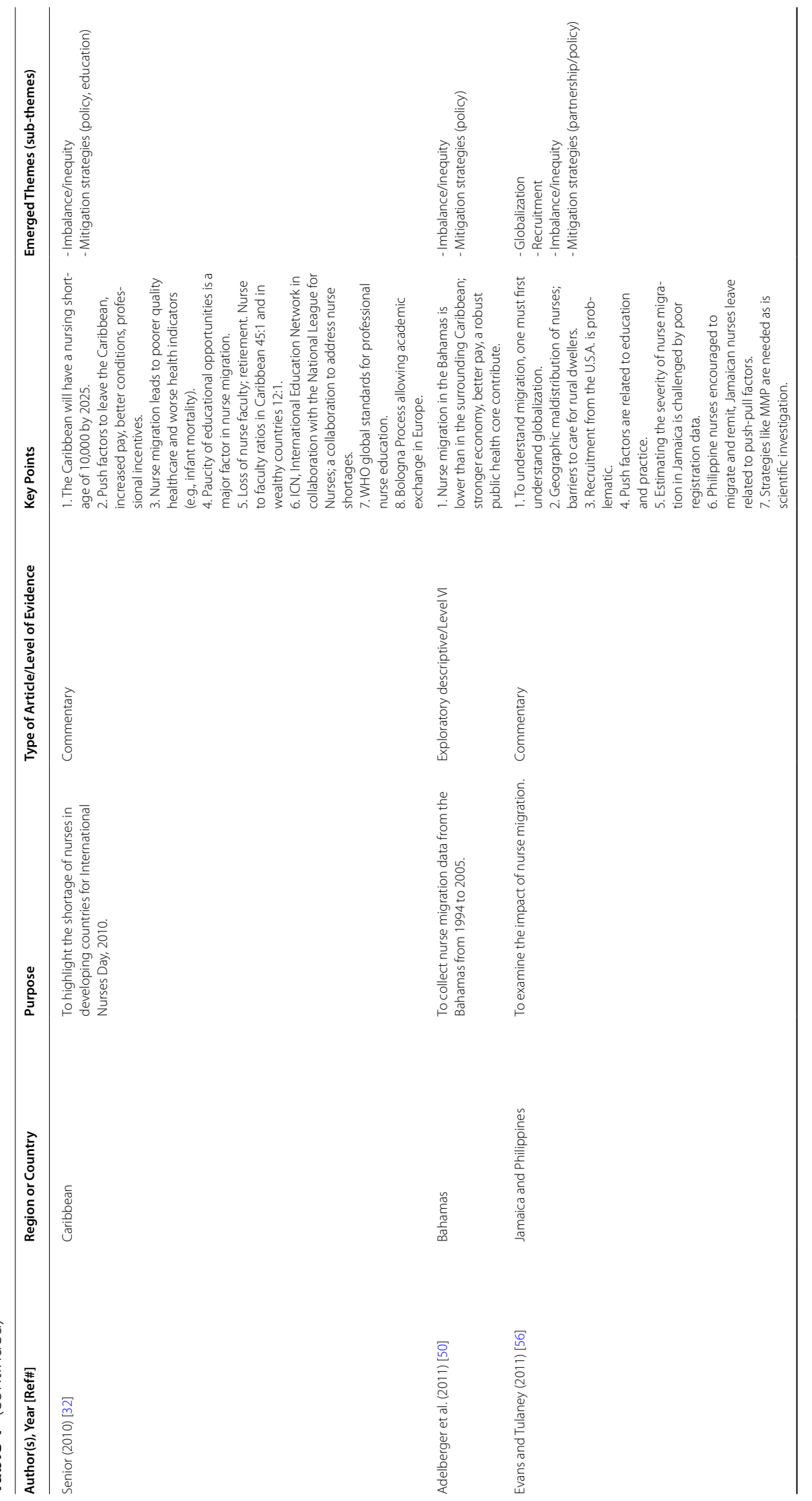




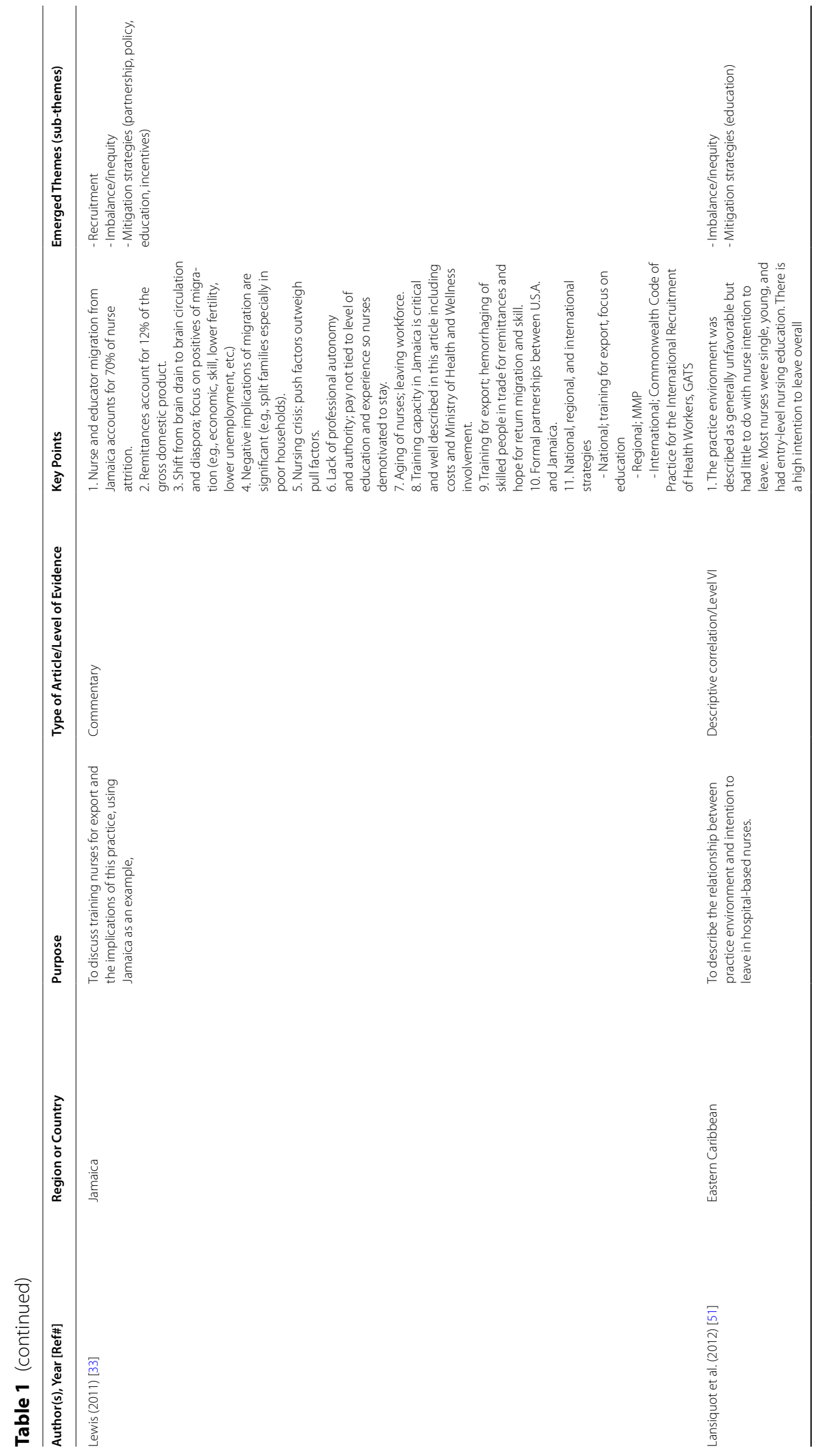




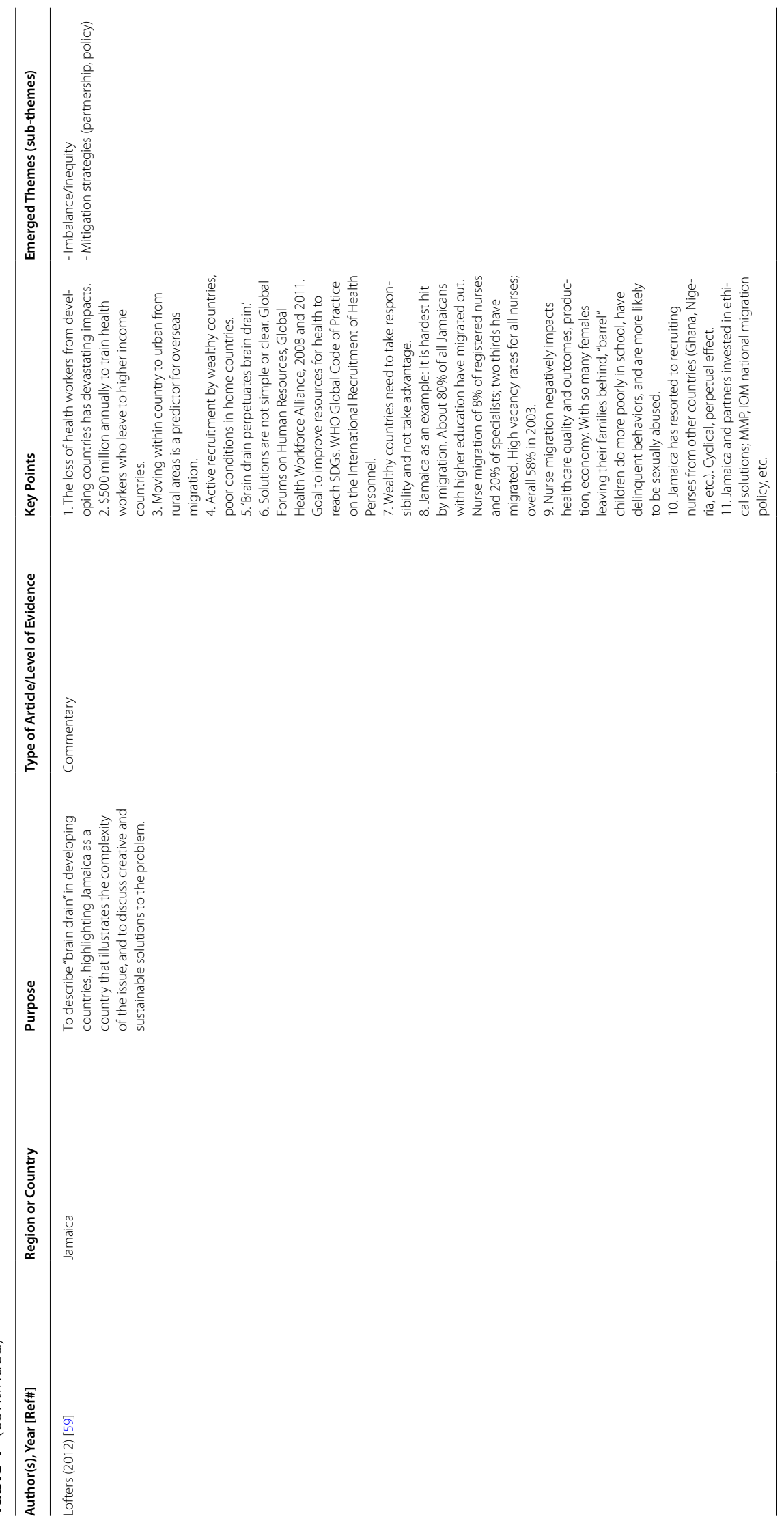




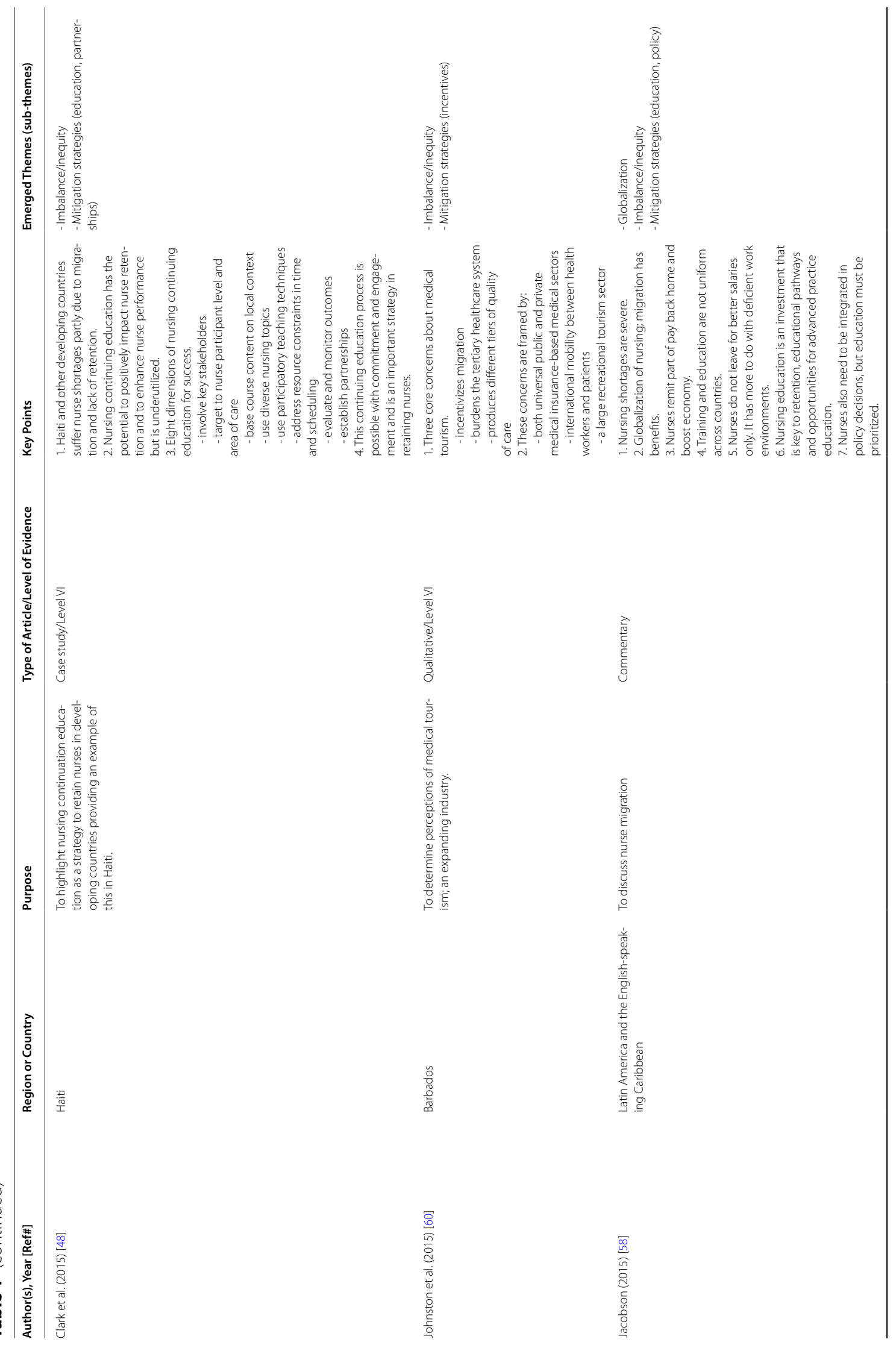




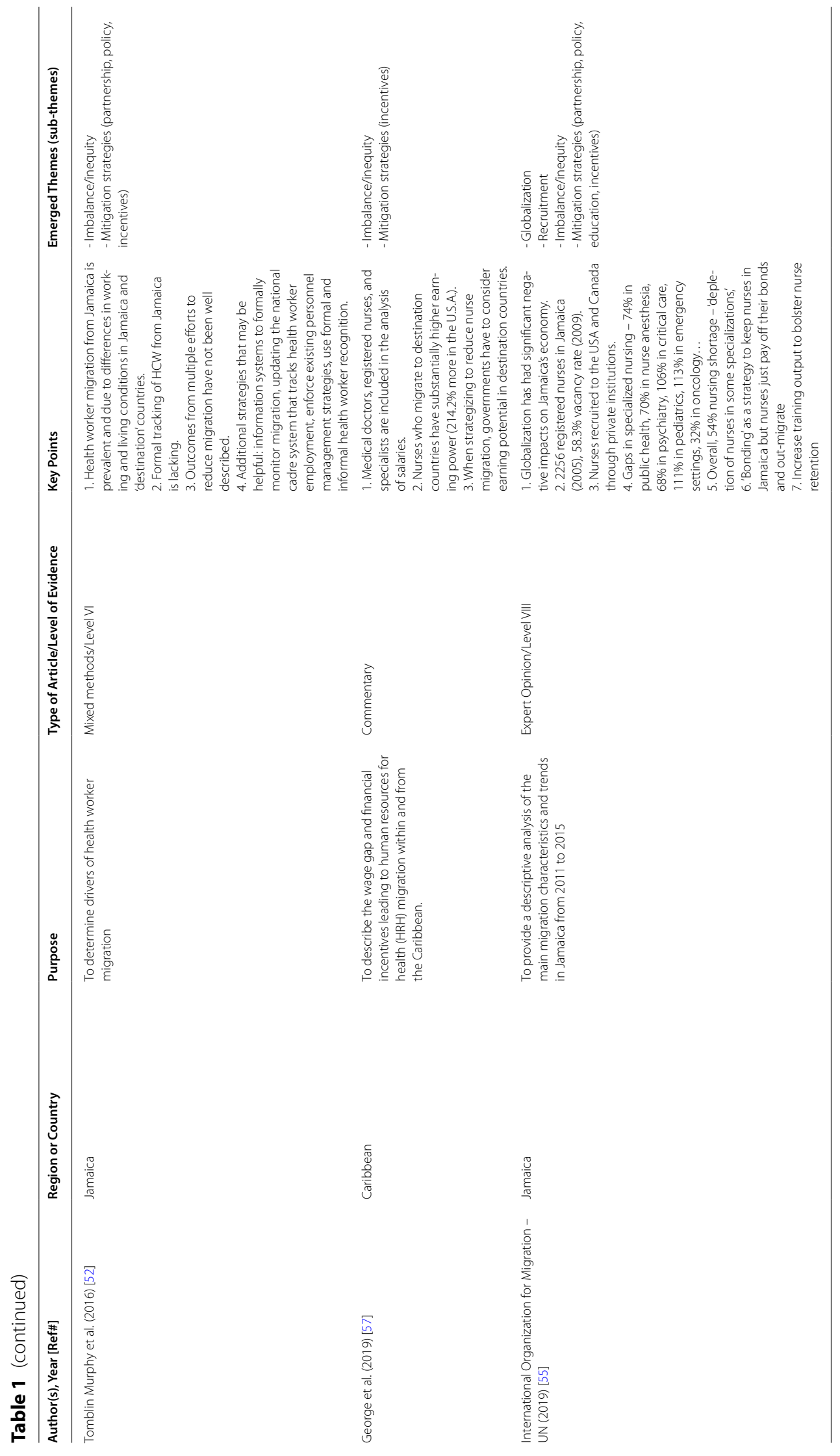




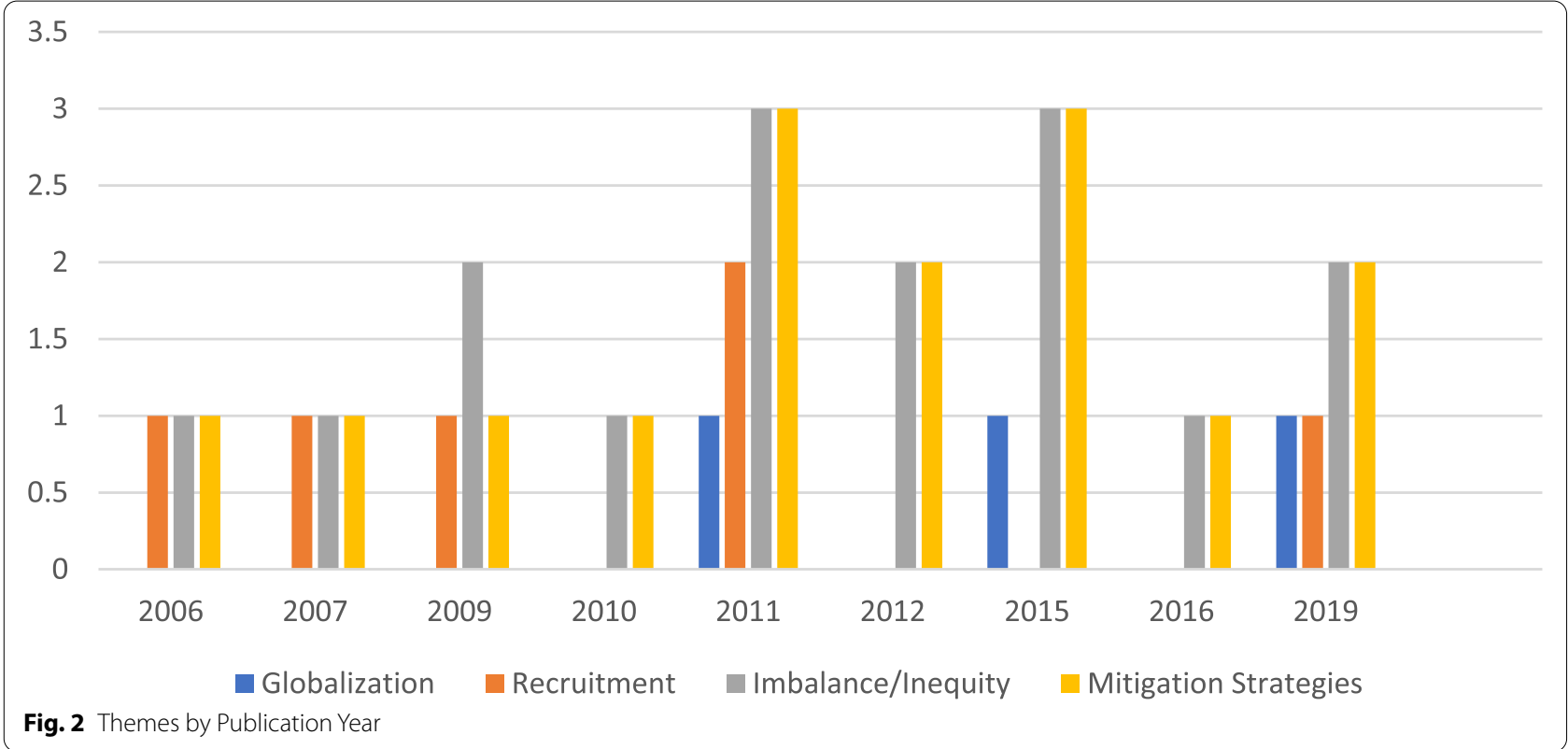

barriers to optimal care. A World Bank report discussed instituting regional recruitment policies in the CARICOM to thwart active recruitment by wealthier countries [54]. The IOM-UN report suggested that some recruitment for tertiary education and employment is through unregistered agencies, and that the welfare of recruits is uncertain, which argues for greater surveillance of recruitment practices [55]. Three articles called attention to training for export; deliberate government policies that focus on training professionals from developing countries to fill positions in wealthier countries that are in short supply $[29,33,54]$. This practice leads to an exodus of skilled people from the CARICOM countries in exchange for salary remittances that boost the economy, and a false hope that these individuals will return home with added skills. Training for export models are heavily utilized in the Philippines but are supported through private funding, which is not readily available in Jamaica. Exporting nurses also leads to ongoing nurse shortages and an exaggerated need for nurse education and training opportunities that are already lacking. Although not specific to palliative care, recruitment of nurses by wealthier countries and training nurses for export could negatively impact palliative care integration in low resource countries.

\section{Imbalance and inequalities}

All 16 articles highlighted the profound imbalance and inequities caused by nurse migration from the CARICOM, with eight articles highlighting Jamaica [29, 30, 33, 52, 54-56, 59]. Generally, imbalance and inequities had to do with nursing shortages, loss of specialists and highly skilled nurses, economic and social impacts, and the resulting poor work conditions in the CARICOM countries. Gender was a key issue related to nurse migration in two articles $[53,59]$. Historically, women migrated to wealthier countries to reunite with their spouses or other family members. However, labor shortages in these countries have led to a 'feminization of migration' with skilled women representing an increasing proportion of the global migrant workforce [53]. Unfortunately, when women leave a country, the remaining female family members become burdened with caregiver responsibilities. Further, gender inequalities in the home countries often continue for skilled migrant women in the receiving countries [53]. Many women who out-migrate leave their children behind, and although they may send financial support for child care, there is an emotional cost to this family separation [53]. The 'barrel children' left behind do more poorly in school, have more delinquent behaviors, and are more likely to be sexually abused [59]. Hence, health system imbalances and inequalities could potentially negatively impact palliative care integration in countries with very limited resources.

\section{Mitigation strategies}

The CARICOM's Managed Migration Program (MMP) highlighted key strategies for recruitment, retention, and training of nurses, terms and conditions of work, valuing the nursing profession, and managed nursing practice $[29,30,33,56,59]$. Fifteen articles suggested mitigation 
strategies which were grouped into four categories: $e d u$ cation, partnerships, policy, and incentives.

Seven articles featured nursing education as a strategy to retain nurses noting the paucity of educational opportunities as a major factor in migration [32, 33, 48, 51, 54, 55, 58]. For instance, Lewis [33] suggested that training capacity for nurses in Jamaica was insufficient and that nurses were demotivated to stay. Clark et al. [48] highlighted continuing education strategies to positively impact nurse retention. Jacobson [58] suggested that investing in nursing education was key to nurse retention and may include educational pathways and opportunities for advanced practice education. The World Bank report heavily focused on nurse training as a key component to mitigate out-migration of nurses [54]. And the IOMUN report discussed increasing nurse training output to improve nurse vacancy rates, particularly in specialty areas such as critical care and public health [55].

Eight articles identified partnerships as a key strategy in addressing migration [29, 30, 33, 48, 52, 54, 56, 59]. For instance, Yan [29] highlighted the MMP's JamaicaFlorida partnership where nurses alternate between the two regions resulting in 'brain gain', or a homecoming of sorts where nurses who have migrated to Florida return to Jamaica and share newly acquired skills and knowledge. Clark et al. [48] discussed partnerships to bolster continuing education opportunities in developing countries, while Lewis and the World Bank report [33, 54] suggested formal USA-Jamaica partnerships to mitigate nurse migration. The World Bank report highlighted a need for Caribbean countries to partner with wealthier countries to increase nurse tutoring capacity, because this is a key deficit in Caribbean nurse training programs [54]. However, the IOM-UN report suggested that Jamaica's partnering through temporary migration with the USA and Canada should continue with caution due to competitiveness with domestic labor that may result in altered and substandard agreements [55].

Policy-related strategies were a focus in 11 articles [29, 30, 32, 33, 50, 52, 54-56, 58, 59]. For example, Tomblin Murphy et al. [52] discussed instituting information systems to formally monitor migration and updating the national cadre system to track health worker employment. Salmon [30] highlighted the General Agreement on Trade and Services (GATS) as a framework for nurse migration. One element of the GATS framework calls for the temporary movement of labor to supply services overseas with return of skilled workers with new knowledge and experiences as a replacement for permanent migration of professionals. This calls for harmonization across countries to ensure that professionals return home after a suitable stay [30]. Lofters [59] discussed policy initiatives that target nurse migration including Global
Forums on Human Resources, the Global Health Workforce Alliance, and the WHO Global Code, pointing out that solutions to migration are not 'simple or clear.' Jacobson [58] highlighted that nurses must be integrated in policy decisions to effectively mitigate migration. The World Bank report [54] underscored multiple policydriven mitigation strategies such as creating barriers to migration and establishing reintegration programs for returning nurses, recruitment codes of practice, mobilizing the inactive supply of nurses, allocating nurses to primary care settings, task-shifting to lower skilled workers, and facilitating private sector investment in nurse training. And the IOM-UN report highlighted 'bonding' as a practice to retain nurses who owe up to 5 years of service as repayment for government-funded education. However, this strategy often fails as nurses simply repay their government bonds and have high potential to outmigrate before the terms of their bond are fulfilled [55].

Incentive-based strategies were discussed in five articles [33, 49, 52, 55, 57]. George et al. [57] focused on the extreme wage gaps between CARICOM countries and 'destination' countries (e.g. nurses make $214 \%$ more in the USA), noting that CARICOM governments must consider earning potential in efforts to retain nurses. Lewis [33] offered that nurses are not motivated to stay in CARICOM nations due to lack of professional autonomy and authority, and that efforts to tie pay and practice privileges to education level and practice experience may be advantageous in mitigating nurse migration. Conversely, Johnston et al. [49] shed light on 'medical tourism' producing an incentive for Barbadian nurses to migrate from public to private medical facilities. Medical tourism is an economic development strategy to attract foreign patients by marketing affordable and accessible medical care [62]. This influx of privately paying tourists draws nurses to the private sector for higher paying jobs and results in shortages and inequitable care for local patients seen in the public health sector [62]. And the IOM-UN report discussed Jamaica's Return of Talent Program, which offers financial incentives for return-migration for specific sectors and occupational groups. This report also highlighted other incentives for return-migration such as supplying job information, linkages with employers, and investment opportunities [55]. Although not specific to palliative care, these mitigation strategies are important to bolstering palliative care integration in countries with low resources.

\section{Discussion}

This critical review was driven by the need to understand how nurse migration might affect palliative care integration in Jamaica. Emerged evidence supports that nurse migration is an ongoing phenomenon that strains health 
systems in CARICOM countries, with Jamaica being the most deeply impacted. Migration rates from some Caribbean countries, such as the Bahamas, are lower for reasons that are not clear but are likely related to wealthier economies and fewer workplace challenges [50]. The inequities and imbalances resulting from nurse migration were described across articles. Negative implications, such as poorer patient outcomes (e.g., infant mortality), were in part attributed to the out-migration of the most skilled nurses. 'Push-factors' such as aggressive recruitment by wealthier countries, lack of continuing educational opportunities, disparate wages, and a lack of professional autonomy and respect were clear contributors. Poor working conditions (e.g. high patient-nurse ratios) may also contribute, but were not necessarily a primary reason for nurse migration [51], although worker dissatisfaction arose as a determinant for out-migration in the World Bank report [54]. Gender inequalities were also implicated as a push-factor for nurse out-migration, negatively impacting females and children left behind [53, 59]. A multitude of mitigation strategies to thwart nurse migration were highlighted including education, partnership, policies, and incentives. Providing educational opportunities and capitalizing on policy initiatives, such as the MMP, stood out as essential strategies to retain Caribbean nurses [48]. However, outcomes were poorly described and it was uncertain if these strategies were sufficient [52]. The World Bank report highlighted several policy initiatives that have potential to mitigate the negative impacts of nurse migration such as reintegration policies and recruitment codes [54]. And the IOM-UN report focused on 'bonding' to keep nurses in Jamaica based on obligations to fulfill up to 5-year positions in return for educational funding, however bond prices may need to be increased to prevent nurses from paying them off and out-migrating [55]. The IOM-UN report framed globalization based on early negative impacts particularly to the agriculture sector leading to overall economic decline, which pushed Jamaicans (including nurses) toward out-migration to the USA and Canada [55]. In a mixed methods dissertation study, although not included in the review based on not meeting inclusion criteria, Russell suggested that the Caribbean has participated in the creation of globalization due to an openness to migration and trade, leading to an internationalization of labor [63]. Russell also discussed the role of well-educated second generation migrants returning to their home countries to bolster social and economic factors [63].

\section{Nurse migration as a facilitator and barrier to palliative care}

The emerged themes of education, partnership, policy, and incentive-based mitigation strategies directly align with the $W H O P H M$ drivers to palliative care integration. These findings suggest that Jamaican nurses will be less apt to migrate with improved educational opportunities and revision of policies to include incentives for advanced education and leadership roles.

Expanding educational opportunities, such as interprofessional palliative care training would allow nurses to work alongside other professionals, opening lines of communication, mutual understanding and respect. Improved renumeration could incentivize nurses to remain in Jamaica, leading to fewer imbalances/inequities in the nursing workforce. Policy changes allowing nurses an expanded scope of practice have the potential to positively influence nurse retention. For instance, granting community-based palliative care practice and opioidbased pain management privileges could entice nurses to remain in the country. A literature search for articles having to do with migration effects on palliative care integration efforts outside the Caribbean revealed a paucity of evidence. The only article identified described Israel's introduction of advanced practice nurses with specialty palliative care training to counter physician workforce shortages and recommendations to rapidly expand the advanced practice nursing role to improve healthcare access and bolster existing resources creating a rich pool of health professionals [64]. Tapping into the pool of second generation migrants with nurse training who have the potential to improve the social and economic picture in Jamaica and the wider Caribbean is another strategy that should be further investigated through policy initiatives [63]. The IOM UN report discussed the potential of highly educated Jamaican diaspora to contribute to strengthening Jamaica's social and economic picture, a tactic that has potential to boost palliative care development [55]. Tailored mitigation strategies to reduce nurse migration from Jamaica are profoundly important when considering palliative care integration and the key roles that nurses can play. In the absence of drastic improvements to educational offerings and restrictive policies related to nurses, out-migration of nurses will most certainly hamper palliative care integration efforts in Jamaica.

Although counter-intuitive, it is important to consider avenues in which nurse migration may benefit palliative care integration in Jamaica. Several identified themes align with the Model of Sustainability in Global Nursing [41]. According to the model, fostering collaborative, cross-cultural partnerships that focus on advancing education, leadership, policy advocacy, and interprofessional collaborations, incentivizes nurses to expand their knowledge and skills, which leads to empowerment and sustained outcomes, such as reduced out-migration. International and interprofessional partnerships promote 
sustainable health system improvements and should be incorporated in efforts to integrate palliative care in Jamaica $[41,65,66]$. These findings are in support of partnerships pursued through the $\mathrm{PAHO} / \mathrm{WHOCC}$ such as the UAB-UWI collaboration $[42,43])$. This type of reciprocal partnership leads to positive sustainable changes, including opportunities to enhance palliative care training and service delivery in both Jamaica and the USA. Similarly, the World Bank report recommends strengthening partnerships to enhance and broaden the role of nurse tutors in Jamaica who are needed to effectively educate and train competent nurses capable of delivering quality palliative care [54]. Given the unknown effect of the COVID-19 pandemic on out-migration, capitalizing on existing partnerships and fostering new cross-border collaborations should become a priority.

\section{Future directions and impact}

Despite an array of mitigation strategies to counteract nurse migration, evidence on their effectiveness is lacking. The four emerged themes, globalization, recruitment, imbalance/ inequities, and mitigation strategies must be considered in efforts to integrate palliative care in Jamaica. Additionally, the impact of collaborative partnerships informed by the WHO PHM and the Model of Sustainability in Global Nursing should be further explored. The hypotheses generated from this review can guide future scientific inquiry:

1. Bolstering palliative care education and training opportunities will incentivize nurses to remain in Jamaica and contribute to palliative care integration efforts.

2. Collaborative partnerships in palliative care education between Jamaica and wealthier countries will lead to sustained retention of nurses in Jamaica.

3. Policies that reward nurses for advanced knowledge and skills in palliative care will incentivize nurses and mitigate out-migration.

The impact of the recent COVID-19 pandemic must be factored into strategies for successfully palliative care integration in Jamaica. Suggestions in the International Council of Nurses (ICN) report, COVID-19 and the International Supply of Nurses [67], align with themes identified in this critical review including education and migration policy. The report highlights Jamaica as a particularly vulnerable country to out-migration of nurses. Given the country's limited domestic training capacity, the impact of COVID-19 on the nursing workforce such as burnout, absenteeism, illness, and death is further magnified [67]. Economic disruption and long-term financial problems are expected to escalate and further exacerbate out-migration.

Cancer Care in the Commonwealth Caribbean in COVID times [68] suggests a need to reframe and reemphasize priorities for cancer care due to the pandemic's effects, which inherently creates a greater need for palliative care. This aligns with a focus on education to increase cancer and palliative care capacity [68]. Models of care that incorporate task-shifting (i.e., from physicians to nurses and from nurses to less-skilled workers) through education, and development of communitybased services to accommodate social distancing and barriers to seeking care must be considered. An example of a strategy through partnerships included the use of telehealth with support from high-resource countries [68] and incorporating nurse tutors in Jamaica through online course experiences [54]. A focus on filtering more nurses into primary care settings through policy initiatives may also bolster community palliative care capacity in Jamaica [54]. Mitigating strategies coupled with travel restrictions that quell migration, may foster improved nurse-retention at least for the near future.

\section{Strengths and limitations}

The investigators' expertise in methodology as well as in the substantive content areas of palliative care, nurse migration, and global nursing is a main strong point of this critical review. Similarly to Rolle-Sands et al. [24], we explored empirical evidence pertaining to the effects of nurse migration on outcomes, including the experiences of those who remain in Jamaica and the outcomes of those they care for. However, we specifically focused on how these outcomes may impact palliative care advancement in Jamaica. Although there was relative paucity of robust studies, sufficient descriptive information and experiences were identified to formulate working hypotheses for future research. An attempt to identify additional resources specific to migration effects on palliative care integration outside of the Caribbean yielded little information. One article highlighted expansion of palliative-trained advanced practice nurses to fill physician workforce gaps in Israel; a strategy that may be useful in the Jamaican context [64].

\section{Conclusions}

This critical review offers a comprehensive overview of the effects of nurse migration on palliative care integration in Jamaica. Emerged themes included: (a) globalization creating opportunities for migration, (b) recruitment of skilled professionals from CARICOM, (c) imbalance and inequities resulting from migration, and (d) mitigation reduction strategies. To fully contribute to palliative care integration, nurses require opportunities for 
education as well as policy support. Without significant policy change, such as expanding the role and capacity of Jamaican nurses, increasing salaries and offering leadership opportunities, nurses will continue to migrate. Continued loss of Jamaica's skilled nursing workforce will negatively impact palliative care integration efforts and is a barrier to meeting the sixty-seventh World Health Assembly recommendations for strengthening palliative care [69]. Formulated hypotheses from this review should guide future investigation of the effects of nurse migration on integration of palliative care in Jamaica. Novel mitigating strategies, and opportunities for enhanced nurse education such as investigating the role of advanced practice nurses with specialty palliative care training, should be considered within Jamaica's healthcare system.

\section{Abbreviations}

CARICOM: Caribbean Community and Common Marketplace; CINAHL: Cumulative Index to Nursing and Allied Health Literature; GATS: General Agreement on Trade and Services; ICN: International Council of Nurses; MMP: Managed Migration Program; PAIS: Public Affairs International Service; PHM: Public Health Model; PRISMA: Preferred Reporting Items for Systematic Reviews; USA.: United States of America; WHO: World Health Organization.

\section{Acknowledgements}

Our thanks to our University of Alabama at Birmingham colleagues including Dr. Jennifer Frank for critically reviewing an earlier draft of this article and Lisa Theus, Program Manager of Global Partnerships, for translating the abstract from English- to Spanish-language.

\section{Authors' contributions}

RE developed and conducted the search strategy, extracted and screened articles, analyzed and synthesized the data, drafted the manuscript. PP and MB provided methodological and content expertise and revised the manuscript. AM conceptualized, appraised and synthesized the data, drafted and critically revised the manuscript. All authors read and approved the final manuscript.

\section{Authors' information}

$\mathrm{RE}$ is a PhD candidate conducting research on advancement of palliative care in Jamaica. MB is internationally recognized in pain and palliative care science. PP conducts research on nursing workforce issues, quality improvement, and patient safety and teaches in the PhD and Executive DNP Programs. AM is known for capacity building in primary health care and developing global nurse leaders.

\section{Funding}

Funding from an American Cancer Society Doctoral Nursing Scholarship will be utilized to cover the Human Resources for Health article processing charges. No other specific grant from any funding agency in the public, commercial, or not-for-profit sectors was utilized for purposes of this work.

\section{Availability of data and materials}

Data sharing is not applicable to this article as no datasets were generated or analyzed during the current study.

\section{Declarations}

\section{Ethics approval and consent to participate}

Not applicable (non-human subjects - review study).

\section{Consent for publication}

Not applicable.

\section{Competing interests}

The authors declare that they have no competing interests.

\section{Author details}

${ }^{1}$ Department of Acute, Chronic, and Continuing Care, School of Nursing, University of Alabama at Birmingham, 1720 2nd Avenue South, Birmingham, AL 35294-1210, USA. ${ }^{2}$ Family, Community and Health Systems Department, School of Nursing, University of Alabama at Birmingham, 1720 2nd Avenue South, Birmingham, AL 35294-1210, USA. ${ }^{3}$ Center for Palliative and Supportive Care, School of Nursing, University of Alabama at Birmingham, 1720 2nd Avenue, South, Birmingham, AL 35294-1210, USA. ${ }^{4}$ PAHO/WHOCC for International Nursing, Family, Community and Health Systems Department, School of Nursing, University of Alabama at Birmingham, 1720 2nd Avenue South, Birmingham, AL 35294-1210, USA.

Received: 15 January 2021 Accepted: 24 September 2021

Published online: 13 October 2021

\section{References}

1. World Health Organization. WHO definition of palliative care. 2020. Available from: https://www.who.int/cancer/palliative/definition/en/. Cited 2020 Feb 25

2. De Lima L. Palliative care and pain treatment in the global health agenda. Pain. 2015;156(Suppl 1):S115-8.

3. Carlson RW, Larsen JK, McClure J, Fitzgerald CL, Venook AP, Benson AB, et al. International adaptations of NCCN clinical practice guidelines in oncology. J Natl Compr Cancer Netw. 2014;12(5):643-8.

4. Ferrell BR, Temel JS, Temin S, Alesi ER, Balboni TA, Basch EM, et al. Integration of palliative care into standard oncology care: American Society of Clinical Oncology clinical practice guideline update. J Clin Oncol. 2017:35(1):96-112.

5. Hannon B, Zimmermann C, Knaul FM, Powell RA, Mwangi-Powell FN, Rodin G. Provision of palliative care in low- and middle-income countries: overcoming obstacles for effective treatment delivery. J Clin Oncol. 2016;34(1):62-8.

6. Hui D, Hannon BL, Zimmermann C, Bruera E. Improving patient and caregiver outcomes in oncology: team-based, timely, and targeted palliative care. CA Cancer J Clin. 2018;68(5):356-76.

7. National Academies of Sciences, Engineering, and Medicine, Health and Medicine Division, Board on Health Care Services, National Cancer Policy Forum. Cancer care in low-resource areas: cancer treatment, palliative care, and survivorship care: proceedings of a workshop. Washington (DC): National Academies Press (US); 2017.

8. Swarm RA, Dans M. NCCN frameworks for resource stratification of NCCN guidelines: adult cancer pain and palliative care. J Natl Compr Cancer Netw. 2018;16(5S):628-31.

9. Brennan F. Palliative care as an international human right. J Pain Symptom Manag. 2007:33(5):494-9.

10. World Health Organization. Global atlas of palliative care at the end of life. 2014.

11. Center to Advance Palliative Care. America's care of serious illness: 2019 state-by-state report card on access to palliative care in our nation's hospitals: CAPC; 2019. https://reportcard.capc.org/.

12. Macpherson C, Chiochankitmun N, Akpinar-Elci M. Hospice and palliation in the English-speaking Caribbean. Camb Q Healthc Ethics. 2014;23(3):341-8.

13. Stoltenberg M, Spence D, Daubman B-R, Greaves N, Edwards R, Bromfield $B$, et al. The central role of provider training in implementing resourcestratified guidelines for palliative care in low-income and middle-income countries: lessons from the Jamaica Cancer Care and Research Institute in the Caribbean and Universidad Católica in Latin America. Cancer. 2020;126(Suppl 10):2448-57.

14. OECD. Recent trends in international migration of doctors, nurses and medical students. Paris: OECD Publishing; 2019.

15. World Health Organization. From brain drain to brain gain: Global Health Workforce Alliance; 2014. Available from: https://www.who.int/ workforcealliance/media/news/2014/from_brain_to_gain/en/. Cited 2019 Dec 3 
16. Yeates $N$. The globalization of nurse migration: policy issues and responses. Int Labour Rev. 2010;149(4):423-40.

17. Ministry of Health and Wellness, Jamaica. Dr. Tufton addresses WHO on migration of nurses. 2017. Available from: https://www.moh.gov.jm/drtufton-addresses-who-on-migration-of-nurses/. Cited 2019 Dec 3.

18. United Nations. Transforming our world: the 2030 agenda for sustainable development. General Assembley 70 session; 2015

19. World Health Organization. WHO global code of practice on the international recruitment of health personnel. Geneva: World Health Organization; 2010.

20. Scheffler RM, Cometto G, Tulenko K, Bruckner T, Liu JX, Keuffel EL. Health workforce requirements for universal health coverage and the Sustainable Development Goals-Background paper N. 1 to the WHO Global Strategy on Human Resources for Health: Workforce 2030. Geneva: World Health Organization; 2016.

21. World Health Organization. State of the world's nursing 2020: investing in education, jobs and leadership: World Health Organization; 2020. Available from: https://www.who.int/publications/i/item/9789240003279. Cited 2020 Sep 24

22. World Health Organization. International migration of health workers: improving international co-operation to address the global health workforce crisis. 2010

23. Schmid K. Emigration of nurses from the Caribbean: causes and consequences for the socio-economic welfare of the country: Trinidad and Tobago, a case study, UN ECLAC Paper; 2003. p. 748.

24. Rolle Sands S, Ingraham K, Salami BO. Caribbean nurse migration-a scoping review. Hum Resour Health. 2020;18(1):19.

25. CARICOM. Caribbean community: a community for all. 2019. Available from: https://caricom.org/about-caricom/who-we-are. Cited 2019 Dec 3.

26. Statistical Institute of Jamaica. Population statistics. 2019. Available from: https://statinja.gov.jm/Demo_SocialStats/PopulationStats.aspx. Cited 2021 Apr 11.

27. Migration Policy Institute. Caribbean immigrants in the United States. 2019. Available from: https://www.migrationpolicy.org/article/caribbeanimmigrants-united-states-2017. Cited 2021 Jul 23.

28. Docquier F, Lohest $O$, Marfouk A. Brain drain in developing regions (1990-2000); 2005.

29. Yan J. Health services delivery: reframing policies for global nursing migration in North America--a Caribbean perspective. Policy Polit Nurs Pract. 2006;7(3 Suppl):71S-5S

30. Salmon ME, Yan J, Hewitt H, Guisinger V. Managed migration: the Caribbean approach to addressing nursing services capacity. Health Serv Res. 2007;42(3 Pt 2):1354-72.

31. Siyam A, Poz MD. Migration of health workers: WHO code of practice and the global economic crisis; 2014

32. Senior K. Wanted: 2.4 million nurses, and that's just in India. Bull World Health Organ. 2010;88(5):327-8.

33. Lewis P. Training nurses for export: a viable development strategy? Soc Econ Stud. 2011;60(2):67-104.

34. Pupino A. The role of Jamaican nurses in health care sectors. 2017. Available from: https://edspace.american.edu/theworldmind/2017/10/13/the role-of-jamaican-nurses-in-health-care-sectors/\#: :targetText=Decades\% 20of\%20nursing\%20migration\%20have,per\%201\%2C000\%20people\% 20in\%202003.\&targetText=The\%20World\%20Bank\%20estimates\%20tha t,nurses\%20by\%20the\%20year\%202025. Cited 2019 Dec 5.

35. World Health Organization. National Health Workforce Accounts data portal. 2020. Available from: https://apps.who.int/nhwaportal/Home/ Index. Cited 2020 Sep 24

36. The World Bank. Nursing shortage in the English-speaking Caribbean hinders the region's development, says the World Bank Report. 2010. Available from: https://www.worldbank.org/en/news/press-release/ 2010/03/02/nursing-shortage-in-the-english-speaking-caribbean-hinde rs-the-regions-development-says-world-bank-report. Cited 2019 Dec 3.

37. Ministry of Health Jamaica. National strategic and action plan for the prevention and control of non-communicable diseases in Jamaica 20132018. 2013.

38. Edmonson C, McCarthy C, Trent-Adams S, McCain C, Marshall J. Emerging global health issues: a nurse's role. Online J Issues Nurs. 2017;22(1):2

39. Stjernswärd J. Palliative care: the public health strategy. J Public Health Policy. 2007;28(1):42-55
40. Stjernswärd J, Foley KM, Ferris FD. The public health strategy for palliative care. J Pain Symptom Manag. 2007:33(5):486-93.

41. Edwards RL, Markaki A, Shirey MR, Patrician PA. A model operationalizing sustainability in global nursing. Nurs Outlook. 2020;68(3):345-54.

42. Watts PI, White T, Rae T, Agu C, Markaki A. Sustaining global partnerships for simulation integration: lessons from the field. Int Nurs Rev. 2020;67(2):168-72.

43. Markaki A, Wingo N, Watts P, Steadman L, Coles K, Rae T, et al. Building capacity for nursing and midwifery education through an asynchronous online course. J Nurs Educ. 2019; (in press).

44. Grant MJ, Booth A. A typology of reviews: an analysis of 14 review types and associated methodologies. Health Inf Libr J. 2009;26(2):91-108.

45. Moher D, Liberati A, Tetzlaff J, Altman DG, PRISMA Group. Preferred reporting items for systematic reviews and meta-analyses: the PRISMA statement. Ann Intern Med. 2009;151(4):264-9 W64.

46. Fineout-Overholt E, Melnyk BM, Stillwell SB, Williamson KM. Evidencebased practice step by step: critical appraisal of the evidence: part I. Am J Nurs. 2010;110(7):47-52.

47. Dang D, Dearholt SL. Johns Hopkins nursing evidence-based practice: model and guidelines: Sigma Theta Tau; 2017. https://books.google. $\mathrm{com} /$ books?hl=en\&lr=\&id=m4k4EAAAQBAJ\&oi=fnd\&pg=PP1\&dq= dang+johns+hopkins+nursing+evidence+based+practive:+model+ and +guidelines\&ots $=$ pULuwHucx9\&sig=v_SUukEfhdrgQaoP8OMv91 C5osU\# $\mathrm{v}=$ onepage.

48. Clark M, Julmisse M, Marcelin N, Merry L, Tuck J, Gagnon AJ. Strengthening healthcare delivery in Haiti through nursing continuing education. Int Nurs Rev. 2015;62(1):54-63.

49. Johnston R, Adams K, Bishop L, Crooks VA, Snyder J. "Best care on home ground" versus "elitist healthcare": concerns and competing expectations for medical tourism development in Barbados. Int J Equity Health. 2015;14:15.

50. Adelberger A, Neely-Smith S, Hagopian A. Estimating nurse migration from the Bahamas between 1994 and 2005: an exploratory descriptive study using a social network identification methodology. Glob Public Health. 2011;6(7):732-45.

51. Lansiquot BA, Tullai-McGuinness S, Madigan E. Turnover intention among hospital-based registered nurses in the Eastern Caribbean. J Nurs Scholarsh. 2012:44(2):187-93.

52. Tomblin Murphy G, Mackenzie A, Waysome B, Guy-Walker J, Palmer R, Elliott Rose A, et al. A mixed-methods study of health worker migration from Jamaica. Hum Resour Health. 2016;14(Suppl 1):36.

53. Jones AD, Bifulco A, Gabe J. Caribbean nurses migrating to the UK: a gender-focused literature review. Int Nurs Rev. 2009;56(3):285-90.

54. World Bank. The nurse labor and education markets in the English-speaking CARICOM: issues and options for reform. Washington, DC: World Bank; 2009.

55. IOM UN Migration. Migration in Jamaica: a country profile 2018. 2019. Available from: https://publications.iom.int/books/migration-jamaicacountry-profile-2018. Cited 2021 Jul 23.

56. Evans MM, Tulaney T. Nurse migration: what is its impact? Medsurg Nurs. 2011;20(6):333-6

57. George G, Rhodes B, Laptiste C. What is the financial incentive to immigrate? An analysis of salary disparities between health workers working in the Caribbean and popular destination countries. BMC Health Serv Res. 2019;19(1):109.

58. Jacobson J. The complexities of nurse migration. Am J Nurs. 2015;115(12):22-3.

59. Lofters AK. The "brain drain" of health care workers: causes, solutions and the example of Jamaica. Can J Public Health. 2012;103(5):e376-8.

60. Johnston R, Crooks VA, Ormond M. Policy implications of medical tourism development in destination countries: revisiting and revising an existing framework by examining the case of Jamaica. Glob Health. 2015:11:29.

61. McMichael AJ, Beaglehole R. The changing global context of public health. Lancet. 2000:356(9228):495-9.

62. Lunt N, Carrera P. Medical tourism: assessing the evidence on treatment abroad. Maturitas. 2010;66(1):27-32.

63. Russell C. Second generation return migrants: the new face of brain circulation in the Caribbean? [undergraduate thesis]; 2021.

64. Aaron EM, Andrews CS. Integration of advanced practice providers into the Israeli healthcare system. Isr J Health Policy Res. 2016:5:7. 
65. Leffers J, Mitchell E. Conceptual model for partnership and sustainability in global health. Public Health Nurs. 2011;28(1):91-102.

66. Upvall MJ, Leffers JM. Revising a conceptual model of partnership and sustainability in global health. Public Health Nurs. 2018;35(3):228-37.

67. Buchan J, Catton H. COVID-19 and the international supply of nurses: International Council of Nurses; 2020. Available from: https://www.icn.ch/ system/files/documents/2020-07/COVID19_internationalsupplyofnurs es_Report_FINAL.pdf. Cited 2020 Sep 29

68. Andall-Brereton G, Bromfield B, Smith S, Spence D. Cancer care in the Commonwealth Caribbean in COVID times. Lancet Oncol. 2020;21(8):1007-9.
69. World Health Assembly. Strengthening of palliative care as a component of comprehensive care throughout the life course. WHA67. 19. 2014.

\section{Publisher's Note}

Springer Nature remains neutral with regard to jurisdictional claims in published maps and institutional affiliations.
Ready to submit your research? Choose BMC and benefit from:

- fast, convenient online submission

- thorough peer review by experienced researchers in your field

- rapid publication on acceptance

- support for research data, including large and complex data types

- gold Open Access which fosters wider collaboration and increased citations

- maximum visibility for your research: over 100M website views per year

At BMC, research is always in progress.

Learn more biomedcentral.com/submissions 